\title{
Reflexões acerca do transtorno de identidade de gênero frente aos serviços de saúde: revisão bibliográfica
}

\section{Reflections on the gender identity disorder in health services: literature review Reflexiones sobre el trastorno de identidad de género ante los servicios de salud: revisión bibliográfica}

\author{
Fernanda Resende Maksoud \\ Senac Goias, Unidade Quirinopolis \\ Xisto Sena Passos \\ Universidade Paulista, Campus Goiania \\ Renata Fabiana Pegoraro ${ }^{1}$ \\ Universidade Federal de Uberlândia
}

\begin{abstract}
Resumo
O objeto do estudo é o transtorno de identidade de gênero relacionado ao diagnóstico, aos serviços de saúde, abordando também a visão dos profissionais de saúde. Trata-se de uma pesquisa descritivo-exploratória, com abordagem qualitativa através da revisão bibliográfica de artigos nacionais identificados por meio de buscas efetuadas nas bases LILACS e Scielo. Os estudos sobre transexualidade referidos aos serviços de saúde e profissionais sugerem que o assunto ainda é alvo de muito preconceito e que já existem serviços de saúde especializados a fim de diagnosticar e tratar esses pacientes. A análise dos estudos permite concluir que a transexualidade ainda é tratada com desconhecimento por alguns profissionais de saúde, uma vez que os transexuais devem ser acolhidos e tratados com respeito e valorização de sua diversidade.

Palavras-chave: Transexualismo; Transtorno de identidade de gênero; Serviços de saúde; Sistema único de saúde.
\end{abstract}

\begin{abstract}
The object of this study is the gender identity disorder related to the diagnosis, health services and also the view of health professionals about it. This is a descriptive-exploratory research, with a qualitative approach through the literature review in national periodical articles available on the bases LILACS and Scielo. Based on these articles, we mighty affirm that the study of transsexuality referred to health services and professionals concern is still a subject of much prejudice, however, despite of it, there are already specialized health services to diagnose and treat these patients. Our analysis shows that transsexuality is still treated with disregard by some health professionals, nevertheless the transsexuals should be welcomed and treated with respect and appreciation for their diversity. Key-words: Transsexualism; Gender identity disorder; Health services; Brazilian health system.
\end{abstract}

\section{Resumen}

El objeto de estudio es el trastorno de identidad de género relacionado al diagnóstico, en los servicios de salud, abordando también la visión de profesionales de la salud. Este es un estudio descriptivo-exploratorio, con enfoque cualitativo a través de la revisión de literatura nacional, identificada a través de búsquedas realizadas en las bases LILACS y Scielo. Los estudios sobre la transexualidad que se refiere a los servicios de salud y a los profesionales indican que el tema aún es objeto de muchos prejuicios y que ya hay servicios de salud especializados para diagnosticar y tratar a estos pacientes. El análisis de los estudios muestra que la transexualidad sigue siendo tratada con desconocimiento por parte de algunos profesionales de la salud, ya que los transexuales deben ser acojidos y tratados con respeto, aprecio y valoración de su diversidad.

Palabras-clave: Transexualidad; Trastorno de identidad de género; Servicios de salud; Sistema de salud.

\section{Introdução}

Este trabalho teve como objetivo realizar uma revisão bibliográfica para identificar publicações nacionais sobre o Transtorno de Identidade de Gênero, com destaque para aquelas que apresentem experiências de atendimento das pessoas nesta condição pelos serviços do Sistema Único de Saúde.

De acordo com a $4^{\mathrm{a}}$ edição do Manual Diagnóstico

Endereço 1: Av. Frederico Tibery, 539 - ap 101 - Bairro Tibery Uberlândia, MG - CEP 38405-074 Telefone: (34) 3212-9682

Endereço 2: Av. Pará, 1720 - Bloco 2C, Sala 21 Bairro Umuarama, Uberlândia - MG, CEP 38405-320 Telefone: (34) 3218-2428 e Estatístico de Transtornos Mentais (DSM IV), o transexualismo está atualmente caracterizado como Transtorno da Identidade de Gênero (TIG) e pode ser definido, de forma bastante breve e simples, como o sentimento de infelicidade ou depressão quanto ao próprio corpo (Áran, 2009). É preciso levar em consideração que a transexualidade não é um ato de vontade pessoal e sim, segundo o Manual, uma patologia como qualquer outra e que, portanto, ninguém a escolhe ter. A troca do nome e do sexo no registro civil é apenas uma das varias etapas do processo de readequação de gênero (Bordas, Márcia \& Goldim, 2000). 
O transexual, apesar do perfeito conhecimento de que nasceu com aquela genitália, não consegue aceitar sua estrutura biológica. Para ele, sua identidade sexual é decididamente heterossexual, pois se reconhece sendo feminino e não masculino ou vice-versa, o que justifica sua reivindicação quanto à readequação genital e de caracteres secundários. O transexual não pode ser confundido com o travesti. Este, através de fetichismo, veste-se nos moldes do sexo oposto, para esconder algo destinado a ser revelado. O travesti não procura cirurgia porque o jogo com seus órgãos genitais constitui fonte de prazer, e não apresenta dúvida quanto à sua identidade sexual. Também não se identifica o transexual com o bissexual, indivíduo que mantém relações sexuais com parceiros de ambos os sexos. E, por fim, também não pode ser confundido com o homossexual, pois esse não nega seu sexo, ou seja, não possui desconforto com seu sexo de origem, apesar de se sentir atraído por indivíduos do mesmo sexo (Matão, Miranda, Campos, Teles \& Mesquita, 2010).

Não há, no Brasil, lei especifica que regule o direito da pessoa transexual alterar o prenome e o sexo no registro civil. Porém, a lei brasileira assegura a toda pessoa o direito a um nome (prenome e sobrenome), protegendo-o contra qualquer exposição que possa causar desprezo público, ainda que não haja intenção difamatória. Sendo assim, as leis gerais vêm permitindo uma interpretação adequada às necessidades do transexual, sendo utilizadas como base situações vivenciadas pelas pessoas portadoras desta patologia no seu dia-a-dia, e fundamentam os pedidos judiciais e as decisões favoráveis a alteração do prenome e sexo no registro civil (Ventura \& Schramm, 2009).

Segundo a Carta dos Direitos dos Usuários da Saúde, é assegurado a qualquer cidadão um atendimento livre de qualquer discriminação, restrição ou negação em função de orientação sexual e identidade de gênero, dentre outras características. É garantido o direito do cidadão de ser identificado pelo nome e sobrenome, existindo em todo o documento do usuário um campo para se registrar o nome pelo qual prefere se chamado, independente do registro civil, não podendo ser tratado de forma desrespeitosa ou preconceituosa. É garantido, também, que em qualquer procedimento diagnóstico, consulta, cirurgia, terapêutica e internação o usuário goze de privacidade e conforto, individualidade e confidencialidade de toda e qualquer informação pessoal (Brasil, 2007).

A equipe de saúde deve estar apta para realizar as intervenções necessárias para o alcance de um melhor resultado do tratamento e padrão estético compatível com o sexo desejado. De acordo com a literatura, o tratamento da transexualidade deve seguir o tripé psicoterapia/ tratamento hormonal/ cirurgia de readequação sexual (Bordas et al, 2000).

Neste sentido, o trabalho desenvolvido teve ênfase na revisão de literatura acerca do transtorno de identidade de gênero, com o intuito de identificar as pesquisas efetuadas e publicadas em língua portuguesa, com destaque para aquelas que apresentassem experiências de atendimento das pessoas nesta condição pelos serviços do Sistema Único de Saúde.

\section{Materiais e métodos}

Esta pesquisa foi desenvolvida a partir de uma revisão bibliográfica que buscou identificar publicações sobre do tema transtorno de identidade de gênero. A busca por artigos foi realizada através das bases de dados LILACS e Scielo; além disso, foi realizada consulta ao acervo da biblioteca da Universidade Paulista-UNIP Campus FlamboyantGoiânia. Foram utilizados os seguintes descritores: "transexualidade", "transexualismo" e "cirurgia de resignação sexual". Foram realizadas as combinações das palavras-chave com o termo "Transtorno de identidade de gênero". No levantamento, não houve a delimitação do período de publicação das produções, e foram considerados somente artigos nacionais escritos em língua portuguesa. A pesquisa foi efetuada em junho de 2011.

No LILACS foram levantados 9 artigos, no SCIELO foram encontrados outros 4, sendo que 2 foram descartados pois também haviam sido identificado pelo LILACS. Nas outras bases de dados utilizadas não foram encontradas publicações referentes ao tema. O total de publicações consideradas para análise geral, portanto, foi igual a 11 .

Os artigos foram selecionados por meio da leitura de seus resumos. Efetuada a seleção, cada artigo foi lido na íntegra e, em seguida, foram identificados os temas abordados em cada publicação. A partir da identificação dos temas presentes em cada artigo, foi efetuada nova leitura de todo o material selecionado e o conteúdo presente em cada um foi agrupado por temas. Foram identificados os seguintes temas: Diagnóstico de Transtorno de identidade de gênero, A regulamentação da cirurgia de transgenitalização no Brasil, Tratamento efetuado por equipe multiprofissional e Tratamento oferecido na rede pública de saúde.

\section{Resultados} Gênero

O diagnóstico do Transtorno de Identidade de

Ao percorrer a literatura relacionada à temática, compreende-se que a transexualidade caracteriza-se por um intenso sofrimento que decorre não apenas por uma percepção de não pertencimento ao sexo biológico, mas, sobretudo pela precariedade social proveniente da não aceitação por parte da sociedade (Lionço, 2009).

Sobre esse transtorno, podemos dizer ainda que, por causas ainda não bem definidas, o indivíduo tem 
a convicção de pertencer ao sexo oposto ao seu. O transexual vive, portanto, numa essencial desarmonia entre quem é, quem acredita ser e a sua aparência externa. Desse modo, desenvolve uma identidade de gênero condizente com a do sexo biológico oposto ao seu. Portanto, para estes indivíduos, o seu corpo é fonte de intenso sofrimento e inconformidade e suas características genitais são rejeitadas dramaticamente, não sendo reconhecidas como possibilidade de prazer. O transexualismo é uma total inversão de identidade de gênero e o objetivo é a mudança de toda a maneira de viver, com todas as conotações sociais, muito além do que uma transformação cirúrgica possa oferecer (Lionço, 2009).

Para o Ministério da Saúde, transexuais são pessoas que não aceitam o sexo que ostentam anatomicamente. $\mathrm{Na}$ transexualidade, o individuo identifica-se com o sexo oposto, embora dotado de genitália externa e interna de um único sexo (Ramsey, 2005).

Para Athayde (2001), o diagnóstico de transtorno de identidade de gênero pode ser um instrumento de patologização, e receber o diagnóstico de transexual pode levar o indivíduo a se sentir doente, errado, disfuncional, anormal, ou seja, sofrer estigmatização consequente ao diagnóstico. Ao ser classificado como um transtorno, não se garante ao indivíduo a autonomia para determinar o próprio gênero.

Val, Melo, Grande e Gomez (2009) abordam que os avanços científicos que ocorrem desde a última metade do século XX têm permitido não apenas que se estude o transtorno, mas ainda uma maior aceitação social e a possibilidade de um tratamento integral que esteja orientado para a redesignação sexual. Apesar disso, o TIG continua sendo pouco conhecido pela maior parte da sociedade, incluindo os profissionais de saúde. Áran, Murta e Zaidhat (2008) salientam que a confirmação do diagnóstico de transexualismo torna-se condição do tratamento, sendo que a cirurgia só poderá ser realizada após, no mínimo, dois anos de acompanhamento psiquiátrico.

Para realizar o diagnóstico, é preciso diferenciar os termos "identidade de gênero" e "orientação sexual". Segundo Áran e Murta (2009) a expressão "identidade de gênero" liga-se à consciência que um individuo tem de ser homem ou mulher. Já a expressão "orientação sexual" encontra-se relacionada a uma atração erótica, podendo ser esta atração homossexual, heterossexual, bissexual ou, ainda, assexual. Os transexuais podem apresentar qualquer uma destas orientações. A orientação sexual para o sexo biológico contrário ou bissexual não é, portanto, um critério de exclusão para o diagnóstico do transtorno de identidade de gênero (Áran \& Murta, 2009).

Segundo Spizzirril, Azevedo e Adbo (2006) para que um indivíduo seja diagnosticado com o transtorno de identidade de gênero é necessário o preenchimento de quatro critérios: a) identificação com o gênero oposto, b) desconforto com seu próprio sexo, c) presença de sofrimento clinicamente significativo e d) prejuízo no funcionamento de alguma área da vida desse individuo. Em linhas gerais, o transexualismo é considerado uma patologia por ser definido como um "transtorno de identidade", dada a não conformidade entre sexo e gênero.

\section{A regulamentação da cirurgia de transgenitalização no Brasil}

A legalização da cirurgia de transgenitalização foi um processo que envolveu diversas discussões que tiveram inicio no Brasil em 1979, quando o Conselho Federal de Medicina foi consultado pela primeira vez sobre a inclusão de próteses mamarias em pacientes do sexo masculino (Cardoso, 2005).

A primeira manifestação favorável à realização de cirurgia de transgenitalização ocorreu no "I Encontro Nacional dos Conselhos de Medicina" no ano de 1997. Nesse Encontro, a cirurgia foi considerada a etapa mais importante no tratamento do transexualismo. Inicialmente o procedimento foi justificado pelo principio da beneficência da Bioética, pois possibilita a integração entre o corpo e a identidade sexual psíquica do interessado (Cardoso, 2005).

A cirurgia de transgenitalização e as hormonioterapias em casos de transexualismo tornaram-se procedimentos médicos legais no Brasil desde 1997, quando da regulamentação de suas condições pela resolução $\mathrm{n}^{\circ} 1.482 / 97$ do Conselho Federal de Medicina, que logo após, em 2002, foi revogada pela resolução do CFM nº $1652 / 2002$, que permanece em vigor.

A regulamentação destes procedimentos pressupõe suas finalidades terapêuticas, o que isentaria os profissionais da caracterização de suas intervenções como atos criminosos segundo o parâmetro do código penal (Val et al, 2009). Com a resolução a transformação cirúrgica da genitália interna e externa e caracteres sexuais não constitui crime de mutilação, pois passa a ter caráter terapêutico específico que busca adequar a genitália ao sexo psíquico. O Conselho Federal de Medicina, por meio da resolução que regulamenta o tratamento, visa estimular o aperfeiçoamento de novas técnicas e estimular a pesquisa em torno da transformação da genitália (Butler, Rios \& Áran, 2009).

São autorizadas as cirurgias para adequação feminina para masculino somente em hospitais universitários ou hospitais públicos que realizem pesquisa na área. Já as cirurgias para adequação masculina para o feminino poderão ocorrer em hospitais públicos ou privados, independente da atividade de pesquisa. Essas exigências existem, pois foram considerados que as neocolpovulvoplastias (construção da genitália feminina), necessárias para transformação do fenótipo masculino para feminino, apresentam bons resultados cirúrgicos nos aspectos 
estético e funcional, ao passo que nas cirurgias de neofaloplastias (construção da genitália masculina) ainda existem dificuldades nas técnicas cirúrgicas na obtenção de bons resultados estéticos e funcionais (Butler et al., 2009).

\section{O tratamento realizado pela equipe de saúde}

Ao longo dos anos, vêm sendo desenvolvidos e aprimorados os procedimentos cirúrgicos da mudança de sexo, ou seja, da construção artificial de algo próximo e com similar funcionalidade da genitália masculina e feminina, com o objetivo de atender às ansiedades dos pacientes transexuais. Existem hoje diversas técnicas e diferentes procedimentos disponíveis, o que aumenta as possibilidades daqueles que desejam optar por tal procedimento (Brasil, 2004). Vale ratificar a importância da cirurgia de transgenitalização, pois ela pode significar uma possibilidade de integração individual e social deste mesmo individuo, dando-lhe a oportunidade de eliminar sua dualidade sexual para que se afirme na qualidade em que seu sexo psicológico o define (Conselho Federal de Medicina, 2002).

A revisão de Spizzirril et al (2006) aponta que o tratamento hormonal é necessário para a modificação dos caracteres secundários. É de fundamental importância estabelecer a dose ideal do hormônio para cada paciente, de acordo com a necessidade de cada um. A maioria dos pacientes chegam aos serviços de saúde já tendo feito uso de algum tipo de hormônio. Para os autores, há necessidade de pesquisas sobre os efeitos colaterais do uso prolongado de hormônios, visto que a terapia é feita para o resto da vida do paciente.

No caso de redesignação sexual de mulheres transexuais, são empregadas: a retirada ou o desmembramento do pênis, a retirada parcial do escroto, orquiectomia bilateral, uretroplastia, construção da neovagina, neoclitoroplastia e neovulvoplastia. Para a modificação dos caracteres sexuais secundários são empregadas a mamoplastia, cricotireoplastia, cirurgia de cordas vocais, cirurgia feminilizante de face e contorno corporal e realização de depilação definitiva. Para cada etapa da tática cirúrgica, seja para a transgenitalização, seja para a modificação dos caracteres secundários, são empregadas diferentes técnicas. Os autores ressaltam que nem todas as cirurgias de modificação de caracteres sexuais secundários são aplicáveis a todas as usuárias, e dependem de resultados da hormonioterapia feminilizante (Áran \& Murta, 2009).

Já na redesignação sexual de homens transexuais, classificada como uma cirurgia experimental, as táticas cirúrgicas empregadas envolvem: a histerossalpingoooforectomia, a colpectomia, a neofaloplastia e a escrotoplastia. Tal qual no caso de transgenitalização de mulheres transexuais, no caso de homens, leva-se em conta a diversidade de técnicas para cada uma das etapas cirúrgicas. Nesses casos, a mastectomia bilateral é definida como cirurgia de caractere sexual secundário e pode ser realizada antes (ou independentemente) da cirurgia genital. São, assim, cirurgias de grande porte com caráter irreversível, o que coloca como fundamental o esclarecimento ao usuário/ usuária de todas as consequências, sejam funcionais, sejam estéticas dos procedimentos, bem como esclarecimento sobre os possíveis riscos. Deste modo, a realização de contatos prévios com os médicos e ainda com pacientes que já realizaram as cirurgias é indicada e pode auxiliar na tomada de decisão com relação à ocorrência ou não da cirurgia (Áran \& Murta, 2009).

A seleção dos pacientes para a cirurgia de transgenitalismo deve obedecer aos critérios da Resolução do CFM para avaliação e acompanhamento por equipe multidisciplinar (médico psiquiatra, cirurgião, endocrinologista, psicólogo e assistente social) por um período mínimo de dois anos, obedecendo aos critérios: a) diagnóstico médico de trangenitalismo; b) maior de 21 anos; c) ausência de características físicas inapropriadas para a cirurgia. Assim, a confirmação do diagnóstico de transexualismo é uma condição para o tratamento e para que a cirurgia ocorra é necessário o acompanhamento por um psiquiatra por período mínimo de dois anos. (Mendonça, 2008). O acompanhamento terapêutico envolve múltiplas ações, como a hormonioterapia, para redução de possíveis danos orgânicos decorrentes do uso prolongado de hormônios; a psicoterapia, não apenas para apoio para o processo de tomada de decisão com relação à cirurgia, mas também para o desenvolvimento de novas estratégias para melhora e ampliação das relações sociais e familiares; intervenções no âmbito da assistência social para superação de processos discriminatórios e excludentes; além de cirurgias complementares. Desta forma o atendimento a usuários transexuais deve se basear na integralidade da atenção, não restringindo ou centralizando a meta terapêutica às cirurgias de transgenitalização (Aran, 2009; Saadeh, 2004).

Uma das primeiras grandes dificuldades na psicoterapia, além da conquista da confiança, é trabalhar o auto-preconceito. Muitos candidatos à cirurgia, nos contatos iniciais com o profissional de saúde, detém uma auto-imagem relacionada a ser uma "aberração" ou "monstro", e depositam na Medicina a salvação ou a condenação ao seu estado. O preconceito social também é um aspecto discutido ao longo das intervenções psicoterápicas. Durante o processo, o indivíduo tem a possibilidade de refletir sobre como as pessoas, no dia a dia, têm dificuldades para perceber, aceitar e respeitar as diferenças entre transexualismo, transvestismo e homossexualidade (Áran \& Murta, 2006).

O transtorno de identidade de gênero e o 
tratamento no sistema público de saúde no Brasil

Com a resolução do CFM que regulamenta a cirurgia de transgenitalização houve um aumento significativo de demanda de auxilio médico por parte dos pacientes transexuais, o que acabou gerando a necessidade de organização de programas assistenciais.

Os processos assistenciais nos serviços de saúde pública obedecem as seguintes etapas: a confirmação do diagnóstico através de avaliação e acompanhamento psiquiátrico regular, psicoterapia individual e de grupo, tratamento de hormonioterapia com objetivo de induzir o aparecimento dos caracteres sexuais secundários compatíveis com a identificação psicossexual do paciente, tratamento cirúrgico e acompanhamento pós-cirúrgico (Cardoso, 2005).

Vários serviços existentes no país já estabelecem contato com uma assessoria jurídica, para indicação de pacientes operados para conseguirem a retificação do nome e sexo no registro civil. Uma importante iniciativa para a promoção do acesso universal ao sistema de saúde foi a Carta dos Direitos dos Usuários da Saúde, que destaca o direito ao uso do nome social, seja nos serviços especializados que atendem os pacientes transexuais ou em qualquer outro serviço da rede de saúde pública, ou seja, o transexual tem seu direito resguardado de ser tratado com o nome que prefere ser chamado. Essa media garante ao transexual uma dignidade até que consiga judicialmente a mudança de seu registro civil (Áran, Murta \& Lionço, 2009).

Desde 2004 a temática referente à assistência a pacientes transexuais tem sido abordada pelo Comitê Técnico Saúde da População de Gays, Lésbicas, Transgêneros e Bissexuais do Ministério da Saúde. Tal Comitê foi instituído através da Portaria/GM N ${ }^{\circ}$ 2227, de 14 de outubro de 2004 e constitui importante iniciativa para fortalecimento de políticas públicas que permitam a inclusão de transexuais na rede pública de saúde no Brasil (Áran et al., 2009).

Recentemente o acesso ao processo transexualizador foi incorporado na rede assistencial do Sistema Único de Saúde (SUS), através da Portaria do Ministro da Saúde nº 1.707, de 18 de agosto de 2008, que delimita os critérios e as condições para o acesso estabelecidos na Resolução CFMn. ${ }^{\circ} 1.652 / 2002$ e dá as seguintes diretrizes para o atendimento e organização dos serviços: "integralidade e humanização da assistência; desenvolvimento de estudos sobre a eficácia, efetividade, custo e benefício e qualidade do processo transexualizador para a pessoa transexual; capacitação, manutenção e educação permanente das equipes" (Ventura \& Schramm, 2009, p.79).

No ano de 2010 foi criada a Politica Nacional de Saúde Integral das lésbicas, gays, bissexuais, transexuais e travestis (LGBTT). Sua criação foi embasada nos princípios assegurados pela Constituição Federal de 1988, que garante a cidadania e dignidade da pessoa humana, devendose promover o bem estar a todos, sem preconceitos de origem, raça, sexo, cor, idade, e quaisquer outras formas de discriminação (Brasil, 2010). Levouse em consideração o princípio do SUS sobre a universalidade do acesso, compreendido como o acesso garantido aos serviços de saúde para toda população, em todos os níveis de assistência, sem preconceitos ou privilégios de qualquer espécie. Outro princípio relacionado é a integralidade, entendida como um conjunto articulado e continuo de ações e serviços preventivos e curativos, individuais e coletivos, exigidos para cada caso, em todos os níveis de complexidade do sistema. Tal politica tem como objetivo geral promover a saúde integral de lésbicas, gays, bissexuais, travestis e transexuais, eliminando a discriminação e o preconceito institucional, contribuindo para a redução das desigualdades e para a consolidação do SUS como sistema universal, integral e equânime (Brasil, 2004, 2010).

Em levantamento realizado por Áran e Murta (2006), os serviços de saúde especializados em transexualidade existentes no Brasil são os seguintes: 1) Programa de Transtorno de Identidade de Gênero (PROTIG) do Hospital de Clínicas de Porto Alegre - UFRGS; 2) Unidade de Urologia Reconstrutora Genital do Hospital Universitário Pedro Ernesto UERJ; 3) Ambulatório de Transexualidade - Projeto Sexualidade (PROSEX) do Instituto de Psiquiatria do Hospital das Clínicas da Faculdade de Medicina da USP; 4) Projeto Transexualismo do Hospital das Clínicas de Goiânia; 5) Programa de Atendimento a Transexuais e Cirurgia de Transgenitalização do Hospital Universitário Clementino Fraga Filho UFRJ; 6) Ambulatório de Endocrinologia Especial (Transtorno de Identidade de Gênero) do Instituto Estadual de Diabetes e Endocrinologia Luiz Capriglione (IEDE); 7) Hospital das Clínicas da UFMG ; 8) Transexualidade - Serviço de Urologia da Faculdade de Medicina de São José do Rio Preto da Faculdade de Medicina e Hospital de Base; 9) Atendimento Ambulatorial a Transexuais do Hospital Universitário de Brasília; 10) Departamento de Psicologia do Instituto Paulista de Sexualidade.

Todos os serviços pesquisados são credenciados pelo SUS, a maioria deles possuem equipe formada por urologista, endocrinologista, ginecologista, cirurgião plástico, psiquiatra, psicólogo, serviço social e apenas os serviços da UERJ e HC-Goiânia possuem enfermeiro envolvido no programa (Áran \& Murta, 2006).

Uma pesquisa realizada no Hospital Universitário Clementino Fraga Filho da UFRJ, a respeito do tratamento de pacientes transexuais, entrevistou pacientes que viviam em uma condição de intenso sofrimento psíquico. A pesquisa registrou tentativas de suicídio, ocorrência de depressão, transtornos alimentares e angustias das mais diversas formas 
(Áran, Zaidhat \& Murta, 2008). As pacientes, durante as consultas, destacaram o desejo de obter uma identidade feminina e não necessariamente de ter relações sexuais. Elas expressaram a vontade de serem vistas e desejadas como mulheres. Na maioria dos relacionamentos, as pacientes não praticavam nenhuma forma de relação sexual. Muitas delas preferiam não ter relações sexuais por não poderem se apresentar como transexuais e por não compreenderem seus genitais como instrumentos de prazer. Muitas iniciavam um relacionamento e o interrompiam por medo da reação do parceiro. A maioria delas relatou grande dificuldade profissional devido ao preconceito, principalmente quanto ao registro civil ser inconivente com a aparência. Relataram, sobretudo, a grande mudança em suas vidas após o inicio do tratamento e a realização da cirurgia de transgenitalização.

Um outro estudo, realizado por Áran e Murta (2009), abordou os serviços brasileiros que prestam assistência a transexuais. No geral, o atendimento é efetuado em hospitais universitários localizados em Estados do Sul e Sudeste do país, dotados de ambulatórios especializados com equipes cujos membros são funcionários do quadro permanente da instituição. Esse estudo destaca como uma das principais dificuldades para o atendimento a capacitação dos profissionais para que a atenção ocorra de forma humanizada e, portanto, também livre de discriminação. De acordo com a Portaria MS/457/2008, homens e mulheres devem ser internados em leitos de enfermarias de acordo com o sexo com o qual se identificam socialmente (Brasil, 2008).

Desde 1997, devido resolução do Conselho Federal de Medicina, houve um crescimento significativo do número de usuários transexuais. Foram colhidos os dados no inicio de 2008 sobre o número de pacientes atendidos nos serviços de saúde brasileiros. Verificouse que 700 mulheres transexuais (MTF) e 120 homens transexuais (FTM) já foram atendidos. Desses, 366 encontram-se ainda em atendimento, sendo 256 mulheres transexuais e 22 homens transexuais. O estudo ainda apontou que 57 mulheres transexuais e 31 homens transexuais encontravam-se em pósoperatório na data da pesquisa (Áran \& Murta, 2009).

Juntamente com esses dados torna-se importante ressaltar que o Ministério da Saúde reconhece que a orientação sexual e a identidade de gênero são determinantes e condicionantes da situação de saúde, e que o mal estar e o sentimento de inadaptação em relação ao sexo anatômico dos usuários transexuais devem ser acolhidos e tratados pelo Sistema Único de Saúde, seguindo os preceitos da universalidade, integralidade e equidade da atenção (Áran \& Murta, 2009).

Um estudo foi realizado por enfermeiros e acadêmicos de enfermagem para conhecer a visão dos acadêmicos de enfermagem e medicina sobre a transexualidade (Matão et al, 2010). Como resultado, os pesquisadores apontaram que, durante a pesquisa, notaram que os pesquisados desconheciam o que realmente seria o transtorno, pois na maioria das vezes havia confusão entre os termos transexual, travesti ou homossexual. Os participantes tratavam o transtorno de forma estereotipada, ficando comprovado o estigma e preconceito para com os transexuais, sendo que não se necessita de formação técnica- cientifica para haver uma postura ética e humanizada. Apresentaram também a visão de que o transexual é culpado por apresentar sua patologia, como se ele escolhesse estar na situação que se encontra. Refletem discriminação e intolerância perante ao tema, apresentaram termos como preconceito, anormal, conflito sexual e safadeza quando perguntados sobre o que lhes remetiam o termo transexualismo. Concluíram que os trabalhadores da área da saúde devem estar cientes ao se depararem com um individuo transexual quando estiverem em atividade profissional, pois os pacientes transexuais possuem os mesmos direitos dos outros pacientes portadores de qualquer outra patologia, que merecem um serviço prestado com respeito e humanização.

\section{Discussão}

Embora discutida por poucos autores no Brasil, a transexualidade, ainda denominada de Transtorno de identidade de gênero, é considerada como patologia pela Organização Mundial de Saúde através do Código Internacional de Doenças CID 10 (Áran, 2009). É preciso destacar que o campo da Psicologia Social realiza intensos debates acerca da temática gênero e sexualidades, a exemplo de Mello et al. (2011).

Existem discussões acerca da despatologização da transexualidade, pois alguns autores justificam que a transexualidade é uma condição na qual o individuo se enquadra, que esta passando por uma transição e que ser tratada como patologia deixará o individuo com um estigma muito maior do que ele já carreg,a consigo (Athayde, 2001). Também justificam a impossibilidade de um diagnóstico certo, uma vez que cada caso é diferente do outro mesmo que a problemática seja a mesma eles possuem um conflito consigo mesmos e não uma doença pré-estabelecida com parâmetros para diagnóstico. O que permite o diagnóstico com precisão é o intenso sofrimento psíquico, social e existencial que aparece através de diferentes manifestações. É entendido que o tratamento não levará a aceitação do corpo físico existente e sim a adequação do físico a mente. Já outros autores defendem que a transexualidade é um transtorno mental e que o seu diagnóstico é imprescindível para o tratamento e o mesmo será definido através da incoerência entre o sexo e o gênero (Spizzirril et al., 2006). Independente de considerada patologia ou não o fato é que os transexuais são indivíduos que vivem em uma luta contra si mesmo e vivem em conflito interno de serem uma coisa e enxergarem no espelho 
outra. É devido esse intenso sofrimento psíquico que muitos acabam praticando tentativas de suicídio, apresentam depressão, transtornos alimentares e angustias das mais diversas formas.

O transexualismo, portanto, nos remete à discussão sobre o conceito de saúde de forma mais ampliada. No Brasil, a saúde é exaustivamente colocada como um direito de todos, a partir do texto da Constituição Federal de 1988. No entanto, as práticas de cuidado à saúde da população, em grande parte reproduzem a atenção à doença, desconsiderando a necessidade de um olhar intersetorial e transdisciplinar para o fenômeno saúde. Nesta perspectiva, podemos pensar saúde como a capacidade do humano para enfrentar novas situações, superar as adversidades e administrar as tensões de modo autônomo, com respeito à sua singularidade (Brasil, 2005). A saúde, compreendida não como ausência de doenças, mas como constructo histórico-cultural, envolve a avaliação das normas, dos valores e das expectativas presentes nos indivíduos e na coletividade em dado momento (Uchôa \& Vida, 1994). Ao seguirmos este raciocínio, o transexualismo pode ser concebido como condição de vida não escolhida pela pessoa e que requer meios interventivos para melhorar o bem estar e qualidade de vida (Brasil, 2005).

Com a regulamentação da cirurgia e com a criação do processo transexualizador no SUS houve grandes avanços no tratamento e desenvolvimento do atendimento nos serviços de saúde. Hoje no Brasil os serviços ainda são em números pequenos, e não contemplam todos os estados brasileiros, pois encontram grandes dificuldades na implantação dos serviços e credenciamento pelo SUS, uma vez que são escassos os profissionais que possuem qualificação e se interessam pelo TIG, essas são as dificuldades encontradas para implantação de novos serviços. Já os serviços existentes encontram como dificuldades a liberação de cirurgias pelo SUS, principalmente as dos pacientes que estão em transição do sexo feminino para o sexo masculino, pois essas cirurgias são ainda de caráter experimental. Onde encontramos uma incoerência, ao fato dos princípios norteadores do processo transexualizador no SUS, não estarem condizentes ao que ele está realizando.

Também a assistência é uma grande dificuldade dos serviços já existentes, pois os profissionais na maioria das vezes não são capacitados, e possuem dificuldades de estabelecer uma assistência humanizada a esse tipo de paciente. Estudos comprovam a visão preconceituosa e errônea que os profissionais apresentam sobre a transexualidade, pois alguns profissionais encaram que os pacientes simplesmente escolheram por realizar a mudança de sexo, não possuem a mínima sensibilidade que um profissional deve ter quando se tratam de vidas, e permanecem sempre fazendo pré-julgamentos. É preciso considerar que profissionais de saúde devem seguir preceitos éticos, tratando todos os pacientes com dignidade, humanização e sem distinção de raça, cor, e sexualidade.

Os entrevistados no estudo de Sampaio e Coelho (2012, p.646) ressaltaram a expectativa de que profissionais de Psicologia envolvidos no cuidado a população transexual estejam capacitados como forma de "não promoverem um maior desconforto, sentimentos de exclusão e discriminação por desconhecimento ou curiosidade, o que, por vezes, pode gerar uma tentativa de promover uma cura ou convencimento da desistência das cirurgias e outras intervenções".

Os transexuais devem sempre ser acolhidos e tratados nos serviços de saúde, seguindo os preceitos da universalidade, integralidade e equidade da atenção, princípios resguardados pelo SUS. Infelizmente os serviços de saúde enfrentam enorme resistência institucional devido não apenas ao preconceito, a homofobia e a discriminação incutidas em algumas práticas de saúde, como também dificuldades de compreensão da importância do principio da equidade. O grande desafio para uma assistência de qualidade ao transexual é o reconhecimento do sofrimento psíquico e a importância de tratar desigualmente os desiguais, como forma de justiça social.

\section{Conclusão}

Nas últimas décadas o tema transexualidade tem adquirido cada vez mais importância sobretudo em função da regulamentação de programas de assistência a pacientes transexuais nos serviços públicos de saúde, o que exige uma reflexão mais rigorosa sobre questões de ordem ética, bioética, jurídica e social.

Considerando que a existência da transexualidade, a qual é revestida de inúmeros preconceitos, os quais invariavelmente afetam e interferem negativamente na vida e diagnóstico dos indivíduos transexuais, é de fundamental importância manter um campo de reflexões sobre o tema, a fim de promover uma postura que permita aos serviços de saúde o acolhimento integral desses indivíduos, valorizando a diversidade. Diante desta reflexão conclui-se que o individuo transexual é portador de um transtorno, porém não deixa de ser uma pessoa que deve ser tratado como qualquer ser humano, sujeito de deveres e obrigações e também detentor de inúmeros direitos garantidos aos cidadãos brasileiros.

\section{Referências}

Áran M. (2009). A gramática normativa do sistema sexogênero. [Versão eletrônica]. Ágora, 9 (1),49-63.

Arán, M., \& Murta, D. (2006). Relatório preliminar dos serviços que prestam assistência a transexuais na rede de saúde pública no Brasil. Rio de Janeiro. Instituto de Medicina Social da Universidade Federal do Rio de Janeiro; 2006. Acessado de http:// pfdc.pgr.mpf.gov.br/atuacao-e-conteudos-de-apoio/publicacoes/ 
direitos-sexuais-e-reprodutivos/direitos-lgbtt/Relatorio_ Preliminar_set_20092.pdf

Arán, M., \& Murta, D. (2009). Do diagnóstico de transtorno de identidade de gênero as redescrições da experiência da transexualidade: uma reflexão sobre gênero, tecnologia e saúde. [Versão eletrônica]. Rev Saúde Coletiva, 19 (1), 15-41.

Arán, M., Murta, D., \& Lionço, T. (2009). Transexualidade e saúde pública no Brasil. [Versão eletrônica]. Ciência e Saúde Coletiva, 14 (4), 1141-1149.

Arán, M., Zaidhat .S., \& Murta, D. (2008). Transexualidade: corpo, subjetividade e saúde coletiva. [Versão eletrônica]. Rev Psic Soc, 20 (1),70-99.

Athayde, A. V.L. (2001). Transexualismo masculino. [Versão eletrônica]. Arq Bras Endocrinol Metab, 45 (4), 407-414.

Bordas, F. C., Marcia, M.R., \& Goldim, J.R. (2000). Aspectos bioéticos e jurídicos do transexualismo. [Versão eletrônica]. Rev HCPA, 20 (2), 168-173.

Brasil. Ministério da Saúde (2004). Conselho nacional de combate à discriminação: programa de combate á violência e a discriminação contra GLTB e promoção da cidadania homossexual. Brasília: Ministério da Saúde; 2004. Acessado de http://www. portal.saude.gov.br.

Brasil. Ministério da Saúde (2005). Curso de formação de facilitadores de educação permanente em saúde: unidade de aprendizagem análise do contexto da gestão e das práticas de saúde. Rio de Janeiro: Ministério da Saúde/FIOCRUZ, 2005. Acessado de http://bvsms.saude.gov.br/bvs/publicacoes/curso_facilitadores unidade_pratica.pdf

Brasil. Ministério da Saúde (2007). Carta dos direitos dos usuários da saúde. Brasília: Ministério da Saúde; 2007.

Brasil. Ministério da Saúde (2008). Portaria $n^{\circ} 457$, de 19 de agosto de 2008. Acessado de http://bvsms.saude.gov.br/bvs/ saudelegis/sas/2008/prt0457_19_08_2008.html.

Brasil. Ministério da Saúde (2010). Politica nacional de saúde integral de lésbicas, gays, travestis e transexuais. Brasília: Ministério da Saúde; 2010. Acessado de http://www. portal.saude. gov.br.

Butler, J., Rios, A., \& Àran, M. (2009). Desdiagnosticando o gênero. [Versão eletrônica]. Rev Saúde Coletiva, 19 (1), 95-126.

Cardoso, F.L. (2005). Inversões do papel de gênero: "drag queens", travestismo e transexualismo. [Versão eletrônica]. Psicol Refex Crit., 18 (3), 421-430.

Conselho Federal de Medicina. (2002). Resolução 1.652 de 2002 (BR) do Conselho Federal de Medicina. Dispõe sobre a cirurgia de transgenitalismo e revoga a Resolução CFM $n^{\circ}$ 1.482/97. Diário Oficial da União; 2 dez 2002. [acesso 10 jan 2011]. Acessado de http://www.portalmedico.org.br/resolução/ $\mathrm{cfm} / 2002 / 1652$ 2002.htm

Lionço, T. (2009). Atenção integral á saúde e diversidade sexual no processo transexualizador do SUS: avanços, impasses, desafios. [Versão eletrônica]. Rev Saúde Coletiva, 19 (1),43-63.

Matão, M. E. L., Miranda, D. B., Campos, P. H. F., Teles, M. N., \& Mesquita, R. L. (2010). Representações sociais da transexualidade: perspectiva dos acadêmicos de enfermagem e medicina. [Versão eletrônica]. Revista Baiana de Saúde Pública, 34 (1), 101-118.

Mello, L., Perilo, M., Braz, C.A. de, \& Pedrosa, C. (2011). Políticas de saúde para lésbicas, gays, bissexuais, travestis e transexuais no Brasil: em busca de universalidade, integralidade e equidade [Versão eletrônica]. Sexualidad, Salud y Sociedad Revista Latinoamericana, 9, 7-28.

Mendonça, M.J.C. (2008) A convivência Afetivo-sexual de mulheres transgenitalizadas. [Tese de Doutorado em Psicologia]. Ribeirão Preto: Faculdade de Filosofia, Ciências e Letras de Ribeirão Preto/ USP.

Ramsey, G. (2005). Transexuais: perguntas e respostas. São Paulo: Summus.

Saadeh, A. (2004). Transtorno de identidade sexual: um estudo psicopatológico de transexualismo masculino e feminino. [Tese de Doutorado em Medicina]. São Paulo: Departamento de Psiquiatria da Faculdade de Medicina/ USP. Acessado de http://www.teses. usp.br/teses/disponiveis/5/5142/tde-09082005-115642/
Sampaio, L. L. P., \& Coelho, M. T. Á. D. (2012). Transexualidade: aspectos psicológicos e novas demandas ao setor saúde [Versão eletrônica]. Interface (Botucatu), 16 (42), 637-649.

Spizzirril, G., Azevedo, R.N., \& Abdo, C.H.N. (2006). Travestismo de duplo papel ou bivalente considerações gerais. [Versão eletrônica]. Diagn Tratamento, 16 (1), 29-32.

Uchôa, E., \& Vidal, J. (1994). Antropologia Médica: Elementos Conceituais e Metodológicos para uma Abordagem da Saúde e da Doença. Cadernos Saúde Pública, 10 (4), 497-504.

Val, A.C., Melo, A.P.S., Grande, I., \& Gomez, E. (2009). Transtorno de identidade e orientação sexual. [Versão eletrônica]. Rev Bras Psiq., 32 (2), 192-193.

Ventura, M., \& Schramm, F.R. (2009). Limites e possibilidades do exercício da autonomia nas praticas terapêuticas de modificação corporal e alteração da identidade sexual. [Versão eletrônica]. Rev Saúde Coletiva, 4 (1), 65-93. 
Sobre os autores:

Fernanda Resende Maksoud - Enfermeira graduada pela Universidade Paulista - UNIP, Campus Goiania.

Xisto Sena Passos - Doutor em Medicina Tropical pela Universidade Federal de Goiás. Professor Titular do Curso de Enfermagem da Universidade Paulista, Campus Goiânia.

Renata Fabiana Pegoraro - Doutora em Psicologia pela Universidade de São Paulo. Professora do Instituto de Psicologia da Universidade Federal de Uberlândia.

E mail: rfpegoraro@yahoo.com.br 